\title{
Source Identification, Emission Characters and Tendency of Atmospheric PAHs in China: A Review
}

\author{
Youping Shou* and Xin Li \\ Key Laboratory of Environmental Protection in Water Transport Engineering Ministry of Communications, Tianjin Research Institute for \\ Water Transport Engineering, 300456Tianjin, P.R. China
}

\begin{abstract}
PAHs are widespread environmental pollutants, which originate mostly from incomplete combustion of fossil fuels and organic materials. Due to their well-known carcinogenic and mutagenic properties in humans, PAHs are a concern to more and more people. This review serves as a database to analyse the major emission sources characters and identify the probable sources of PAHs by using diagnostic ratio and principal component analysis. Estimation of PAHs emission in China and toxic equivalency factors of priority PAHs considered by USEPA were also conducted, contributing to establish policies for control the pollution of PAHs in China.
\end{abstract}

\section{Introduction}

Polycyclic aromatic hydrocarbons (PAHs) compounds are a class of complex organic chemicals, which include carbon and hydrogen with a fused ring structure containing at least 2 benzene rings. PAHs are widespread environmental pollutants; most of them originate from incomplete combustion of fossil fuels and organic materials. Although some natural sources (volcanoes and forest fires) can contribute to the PAHs burden, human activities contribute most to PAHs emissions and the sources are entirely anthropogenic in urban and industrial atmospheres [1].

Due to their toxic, carcinogenic and mutagenic properties, PAHs are a concern to more and more people and have been widely studied in various environmental and biologic compartments [2].

Rapid industrialization and economic development has occurred in China since the 1980s, therefore may increase the emission of various pollutants, including PAHs. In China, the total PAHs emission in 2003 was estimated to be about 25,300 tons [3]. Emission from biofuel burning, domestic coal combustion, and industry emission were more significant than before. Considering the increasing evidence of the ubiquitous presence of PAHs and health risk associated with their exposure, this study examines the literature about the character, toxicity and source profile of PAHs in order to provide a logical structure to the information and could contribute to establish policies for control the pollution of PAHs in China.

\section{Priority PAHs and toxic equivalency factors}

Because higher concentrations usually found in the environment and suspected to be more harmful for people than others, 16 priority PAHs listed in Table 1 was considered by The United States Environmental Protection Agency (USEPA). When emitted to the atmospheric environment, PAHs are presented both in vapor and particle phases. PAHs with lower molecular weight (2-3 rings) tend to be more concentrated in the vapor-phase and can be scavenged by precipitation due to their higher solubility, while those with higher molecular weight (4-6 rings) are presented in particulate phase [4].

Table 1. USEPA priority PAHs and their phase distribution.

\begin{tabular}{ccc}
\hline PAHs & Abb. & Particle/Gas Phase Distribution \\
\hline Naphthalene & Nap & Gas Phase \\
Acenaphthene & Ane & Gas Phase \\
Acenaphthylene & Acy & Gas Phase \\
Fluorene & Flu & Gas Phase \\
Anthracene & $\mathrm{AnT}$ & Particle/Gas Phase \\
Phenanthrene & $\mathrm{PhA}$ & Particle/Gas Phase \\
Pyrene & $\mathrm{Pyr}$ & Particle/Gas Phase \\
Fluoranthene & $\mathrm{FluA}$ & Particle/Gas Phase \\
Benz[a] Anthracene & $\mathrm{BaA}$ & Particle Phase \\
Chrysene & $\mathrm{Chr}$ & Particle Phase \\
Benzo[b] Fluoranthene & $\mathrm{BbF}$ & Particle Phase \\
Benzo[k] Fluoranthene & $\mathrm{BkF}$ & Particle Phase \\
Benzo[a] Pyrene & $\mathrm{BaP}$ & Particle Phase \\
Dibenz[a,h] & $\mathrm{DbA}$ & Particle Phase \\
Anthracene & $\mathrm{BP}$ & Particle Phase \\
Benzo[ghi] Perylene & $\mathrm{BP}$ & Particle Phase \\
Indeno[1,2,3-c,d] & $\mathrm{InP}$ & \\
Pyrene &
\end{tabular}

Lower molecular weight (LMW) PAHs were considered less carcinogenic and mutagenic properties, however, recent research showed that they can react with other pollutants to form more toxic compounds [5]. In addition, PAHs concentrations associated with particulate matter (PM) are highly dependent on the particle size partitions and the highest concentrations are found in fine particles [6].

Many countries have added PAHs to their hazardous air pollutants lists but till date there is no strict ambient air quality standard for PAHs. Among these PAHs compounds, the best known $\mathrm{PAH}$ is $\mathrm{BaP}$, which contains 5 rings. Due to its strong carcinogenicity and severe public health, $\mathrm{BaP}$ was monitored in nearly all the studies. According to China National Atmospheric Environmental Standard, the permissible limit of $\mathrm{BaP}$ in atmospheric environment is $10 \mathrm{ng} / \mathrm{m}^{3}$.

$\mathrm{BaP}$ is also the only $\mathrm{PAH}$ for which toxicological data are sufficient for derivation of a carcinogenic potency factor among all known potentially carcinogenic PAHs [7]. The toxic equivalency factors (TEFs) were used to quantify the carcinogenicity of other PAHs relative to $\mathrm{BaP}$. According to the USEPA, calculated TEFs for BaA, 
$\mathrm{BaP}, \mathrm{BbF}, \mathrm{BkF}, \mathrm{InP}, \mathrm{DbA}$ and $\mathrm{Chr}$ are $0.1,1,0.1,0.01$, $0.1,1$ and 0.001 respectively and the total BaP-equivalent concentration could be calculated by equation below:

Total BaP-Equivalent Concentration $=\mathrm{i} \mathrm{Ci} \times \mathrm{TEFi}$

$\mathrm{Ci}$ is the concentration of individual $\mathrm{PAH}$ in the above. Meanwhile TEFi is the corresponding toxic equivalency factor.

\section{Sources of PAHs}

\subsection{Domestic emissions}

PAHs could be found in crude oil, roofing tar or coal tar, and some of which could be used in medicine or make dyes and pesticides for commercial use (including Nap, Flu, AnT, PhA, FluA, and Pyr). However, most PAHs of anthropogenic are produced during the incomplete combustion and pyrolysis of fossil fuels or wood, and from the release of petroleum products.

The emission of PAHs by anthropogenic combustion sources have been analyzed in some research before. The main categories of PAHs emission are conducted as domestic, mobile, industrial and agricultural sources [8].

Domestic emissions are mainly from the burning of coal, gas, oil or some other organic substances like tobacco or char broiled meat. In some region of China, wood or crop waste were also been extensively used for daily cooking, these activities also increase PAHs discharge. Furthermore, the characteristic Chinese stirfrying cooking process have been considered has significant contribution to PAHs emission.

16 Priority PAHs recommended by US EPA have

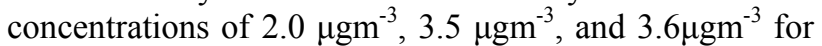
respective combustion activities over $45-60$ min cooking period. And for $\mathrm{BaP}$, the concentration ranged from 1.3$9.3{\mu \mathrm{gm}^{-3}}$ over average sampling periods of $15-30 \mathrm{~min}$ [9]. In residential combustion, the rank of coal and the burning condition are important factors that affect PAHs emission. Coals with higher volatile content are more difficult to complete combustion and are likely to produce more PAHs when burned. Anthracite coal containing little volatile matter can burn more completely and emit PAHs with a mass that is three orders of magnitude lower than bituminous or sub-bituminous coals (which contain high volatile content, yield more PAHs in residential combustion). While, Smoky coal emits parent PAHs and alkylated PAHs when burned.

Burning conditions also influenced PAH emissions. Poor air supply in residential burning may be responded for the high production of PAHs. While, although most of the power plant used fuels as bituminous coals, largescale combustors have much low PAH emission, even lower than that from anthracite in residential combustion. Ledesma et al. [10] showed that most of the PAH mass is produced when the oxygen ratio is under 30\% during bituminous coal burning. Besides, different cooking practices also have different PAHs emission, frying is considered to produce larger amount of PAHs compared to broiling practice. And lard used in cooking seemed to produce more PAHs than rapeseed oil and soybean oil [11]. Further, it has also been noticed that smoldering combustion emits 4-5 times more PAHs than flaming combustion. In contrast, an increase in cooking temperature generally increased the production of most PAHs.

\subsection{Mobile sources}

Mobile sources mainly include the emission from vehicles such as automobiles, aircraft, shipping or railways. In urban areas, vehicle exhaust (diesel, leaded and unleaded gasoline) has been one of the largest sources of PAHs production. Factors including engine type, fuel type and start conditions all affected PAHs emissions. In general, gasoline engines produced PAHs of higher molecular weight such as $\mathrm{BkF}$ and $\mathrm{BP}$, while diesel engines emitted lighter PAHs such as Ane and Acy. Though diesel engines may emit more PAHs, compounds of emissions were less toxic compared to those from gasoline engines. Vehicles under cold start have higher PAHs emissions, especially for gasoline cars at low speed. Previous research [12] found that gasoline vehicles under cold start have around 10 times higher PAHs emission than diesel vehicles. And with the increase of mileage, vehicles automobile would produce more PAHs including Pyr, BaP and BP. Congested traffic conditions or traveling in short distant would also increase the PAHs emissions. However, the use of catalytic converters has been found to have a significant effect on the reduction of the PAHs emissions and higher molecular weight PAHs diminished rapidly when the air/fuel combustion ratio increased [8].

\subsection{Industrial and agricultural emissions}

Industrial emissions are the most common and important sources of PAHs input. The sources cover a lot of industries, such us petrochemical industries, rubber manufacturing, aluminum production, coke production, waste incineration, and heat/power production. Some research has been done in these areas. Prakash and Singh [13] analysed PAHs emission from incineration of cellulose waste filters from acrylic industry and found that the optimum incineration temperature for $16 \mathrm{PAHs}$ was $700-800^{\circ} \mathrm{C}$ with an air flow rate of $1-2 \mathrm{~L} \mathrm{~min}-1$ and at $900^{\circ} \mathrm{C}$ with airflow rate of $2-3 \mathrm{~L} \mathrm{~min}-1$. And in Chen et al. research [14], the mean content of total PAHs was $77 \mu \mathrm{g} / \mathrm{g}$ generated in a waste-tire pyrolysis process with main compounds of InP, DbA and $\mathrm{BaP}$.

Agricultural sources of PAHs emission include the stubble burning, open burning of brushwood or straw and open burning of moorland heather for regeneration purposes. Though in some developed countries, there are policies to regulate these activities, however, biomass burning seems to be popular in developing countries. Due to occurrence and uncertainty of these activities, emissions of PAHs from agricultural sources are difficult to quantify and may contribute significantly PAHs emission to the environment. Lai et al. [15] analyzed PAHs emission from burning of rice straw in agriculture country of Taiwan, found that open burning of rice straws was estimated to contribute approximately $6.3 \%-24.6 \%$ 
to total atmospheric PAHs at the two sites. And in Jenkins et al. study [16], emission factors for 19 polycyclic aromatic hydrocarbons were measured during wind tunnel simulations of open burning for agricultural and forest biomass fuels including cereal grasses, agricultural tree pruning, and fir and pine wood (slash). The result showed that yields of total PAH varied from 5 to $683 \mathrm{mg} / \mathrm{kg}$ depending principally on burning conditions and to a lesser extent on fuel type.

\section{Identification of sources}

\subsection{Diagnostic ratios of PAHs}

Several methods can be used to qualitatively and quantitively identify the probable sources of PAHs. Commonly used methods include Diagnostic Ratios of PAHs to do qualitative analysis and principal components analysis to do quantities' analysis.

Although several constraints exist, molecular ratios of some marker PAHs have been used to identify sources of PAHs in the environment. Ratios of specific individual PAHs are characteristic of different sources [17]. The indications of common diagnostic ratios common used in research $\quad(\mathrm{PhA} /[\mathrm{PhA}+\mathrm{AnT}], \quad \mathrm{FluA} /[\mathrm{FluA}+\mathrm{Pyr}]$, $\mathrm{BaA} /[\mathrm{BaA}+\mathrm{Chr}]$ and $\mathrm{InP} /[\mathrm{InP}+\mathrm{BP}])$ are listed in Table 2.

Table 2. PAHs diagnostic ratios used as source indicator.

\begin{tabular}{cc}
\hline Diagnostic Ratios & Source Indicator \\
\hline & 0.5 gasoline \\
$\mathrm{PhA} /(\mathrm{PhA}+\mathrm{AnT})$ & 0.65 diesel \\
& 0.76 coal \\
& $<0.4$ unburned petroleum \\
FluA/( FluA + Pyr $)$ & $0.4 \sim 0.5$ liquid fossil fuels \\
& $>0.5$ coal and wood \\
$\mathrm{BaA} /(\mathrm{BaA}+\mathrm{Chr})$ & $>0.35$ combustion sources \\
& $<0.2$ petrogenic \\
$\mathrm{InP} /(\mathrm{InP}+\mathrm{BP})$ & 0.18 Cars \\
& 0.57 Diesel \\
& 0.62 Wood burning \\
\hline
\end{tabular}

Khalili et al. [18] found that the ratio $\mathrm{PhA} / \mathrm{PhA}+\mathrm{AnT}$ was 0.65 indicated diesel emissions, 0.50 for gasoline emission and 0.76 for coal combustion sources. Another widely used indicator is concentration ratio of fluoranthene to the sum of fluoranthene and pyrene, FluA/(FluA+Pyr) ratio lower than 0.4 implies the predominance of unburned petroleum sources; a ratio from 0.4 to 0.5 indicates the combustion of liquid fossil fuels sources and a ratio higher than 0.5 suggests grass, wood, and coal combustion sources. $\mathrm{BaA} /(\mathrm{BaA}+\mathrm{Chr})$ is also indicative of the sources. A ratio higher than 0.35 signals pyrolytic sources, lower than 0.2 indicates petrogenic sources, and between 0.2 and 0.35 could be either petrogenic or pyrolytic sources.

Another molecular ratio that has been proposed to differentiate the source of $\mathrm{PAHs}$ is $\mathrm{InP} /(\mathrm{InP}+\mathrm{BP})$ with 0.18 being defined as the cars emissions. The ratio of 0.37 indicates diesel emission sources, and the ratio of 0.56 and 0.62 suggested coal emissions and wooding burning sources respectively. However, these ratios introduced before should be used in combination to avoid erroneous conclusions regarding origins of PAHs.

\subsection{Principal components analysis}

Principal components analysis is the widely used mathematical statistics technique to quantify PAH sources. PCA could reduce the number of variables by simplifies the interpretation of complex systems with retaining the original information effectively and transform the original set of variables into a smaller set of linear combinations. Variables with similar characteristics are grouped into factors. The principal components which present the maximum percentage of total variance of the data set are used as factors. Loading determines the most representative PAHs compounds in each factor. These factors can be interpreted as emission sources to indicate PAHs sources.

In research conducted before, high loading for FluA, Pyr and $\mathrm{PhA}$ was considered the major component of the emissions from coal combustion. Guo et al. suggested that $\mathrm{BaA}, \mathrm{BaP}, \mathrm{BbF}, \mathrm{BP}$ and $\mathrm{InP}$ as source markers for gasoline emissions. Ane and Acy could result from unburned fossil fuels or stationary sources. The presence of Flu, AnT and Chr can be attributed to coal combustion and vehicular emissions. Where $\mathrm{BkF}$ is an indicator of diesel-powered vehicle emissions and BP suggested some vehicle emissions [3, 4].

It is suggested that could have better insight of PAHs emission sources by using PCA separately for both vapor and particulate phase PAHs contrast to that for total PAHs concentrations (vapor plus particulate phase).

\section{Emission estimation of PAHs in China}

In China, the total PAHs emission in 2003 was estimated to be about 25,300 tons, were comparable with the amount emitted in the United States in 1990 (26,500 tons). However, the total emission of seven carcinogenic PAH components (BaA, Chr, BbF, BkF, BaP, InP and DbA) from China (3460 tons) was much higher than that emitted from the United States in 1990 (2000 tons) or 1996 (1400 tons).

The relatively higher fraction of carcinogenic species in the PAH emission profile in China was closely related to the emission source pattern. Emissions from biofuel burning, domestic coal combustion and industry emission were more significant than other countries, which presented higher portion of HMW species with carcinogenic potential. Different from other countries, biofuel burning was the most important burden for 16 Priority PAHs, contributing $60 \%$ of the total in China. Domestic coal combustion was another important PAH source in China, which contributed $20 \%$ of the total and the emission profile was much different than other countries such as United States and United Kingdom. Coking industry, another contributor of PAH emission, are accounting for $16 \%$ of the total 16 Priority PAHs in China. Compared to other countries, petroleum was not a major contributor, accounting for only $2.2 \%$ of the total 16 Priority PAH emission. 
Rapid industrialization, economic and population development has occurred in China since the 1980s. With the development, the consumption of domestic coal was significant increasing, emission of 16 Priority PAHs and $\mathrm{BaP}$ in China increased $28 \%$ and $40 \%$, respectively during the period from 1980 to 1990 . However, with the new round industrialization and urbanization occurred, population growth would be unavoidable. Domestic coal consumption would also increase as the result of population growth, and would lead the PAH emission up again. The development of coke industries was another reason for PAHs emission increasing. With annual production of coke jumped from 122 million tons in 2000 to 178 million tons in 2003, PAH emission has also been grown up and the rising tendency would be last if no measures are taken, either to reduce the production or to reduce the emission during production. For China, though energy consumption went up continuously during the past two decades, PAH emission was determined by the amount of domestic coal consumption, coke production, and the efficiency of energy utilization.

\section{Summary}

Rapid industrialization and economic development has occurred in China. With the development, PAHs emissions were significant increasing. This review introduced the priority PAHs considered by USEPA and their toxic equivalency factors. The important emission sources of PAHs including domestic emissions, mobile sources; industrial and agricultural sources were also analyzed. The applications of diagnostic ratio and PCA to identify the emission sources have been discussed in this review. Estimation of PAHs emission in China was also conducted, contributing to establish policies for control the pollution of PAHs in China.

\section{Acknowledgement}

This work was supported by the Research of VOCs emissions inventory and reuse technology in loading and unloading crude oil in water transport (TKS140218).

\section{References}

[1] C.H. Vasilakos, N. Levi, T.H. Maggos, J. Hatzianestis, J. Michopoulos, C. Helmis. Journal of Hazardous materials, 140, 45 (2007)

[2] K. Ravindra, E. Wauters, R. Van Grieken. Science of the Total Environment, 396, 100 (2008)

[3] P.H. Li, Y. Wang, Y.H. Li, Z.F. Wang, H.Y. Zhang, P.J. Xu, W.X. Wang. Atmospheric Environment, 44, 1996 (2010)

[4] Y. Wang, P.H. Li, H.L. Li, X.H. Liu, W.X. Wang. Atmospheric Research, 95, 17 (2010)

[5] F.L. Tian, J.W. Chen, X.L. Qiao, Z. Wang, P. Yang, D.G. Wang. Atmospheric Environment, 43, 2747 (2009)

[6] A.M. Caricchia, S. Chiavarini, M. Pezza. Atmospheric Environment, 33, 3731 (1999)
[7] T. Agarwal, P.S. Khillare, V. Shridhar, S. Ray. Journal of Hazardous Materials, 163, 1033 (2009)

[8] K. Ravindra, R. Sokhi, R. Van Grieken. Atmospheric Environment, 42, 2895 (2008)

[9] C.V. Raiyani, J.P. Jani, N.M. Desai, P.G. Shah, D.J. Parikh, S.K. Kashyap. Environmental Contamination and Toxicology, 50, 757 (1993)

[10]E.B. Ledesma, M.A. Kalish, P.F. Nelson, M.J. Wornat, J.C. Mackie, Fuel, 79, 1801 (2000)

[11]L.Z. Zhu, J. Wang. Chemosphere, 50, 611 (2003)

[12]O. Devos, E. Combet, P. Tassel, L. Paturel, Polycyclic Aromatic Compounds, 26, 69 (2006)

[13] V. Prakash, S. Singh. Environmental Monitoring and Assessment, 163, 591 (2010)

[14] S.J. Chen, H.B. Su, J.E. Chang, W.J. Lee, K.L. Huang, L.T. Hsieh, Y.C. Huang, W.Y. Lin, C.C. Lin. Atmospheric Environment, 41, 1209 (2007)

[15]C.H. Lai, K.S. Chen, H.K. Wang. Journal of Environmental Sciences, 21, 1200 (2009)

[16]B.M. Jenkins, A.D. Jones, S.Q. Turn, R.B. Williams. Environmental Science and Technology, 30, 2462 (1996)

[17] W. Zhang, S.C. Zhang, C. Wan, D.P. Yue, Y.B. Ye, X.J. Wang. Environmental Pollution, 153, 594 (2008)

[18]N.R. Khalili, P.A. Scheff, T.M. Holsen. Atmospheric Environment, 29, 533 (1995) 